\title{
We Still Have a Long Way to Go
}

\section{Black Mental Health. Patients, Providers and Systems. Edited by Ezra E. H. Griffith, Billy E. Jones, Altha J. Stewart; Washington DC; American Psychiatric Association Publishing; 2019; ISBN 9781615372065; Pp. 382; \$49.00 Paperback}

\author{
Mary K. Morreale ${ }^{1}$ D
}

Received: 3 October 2020 / Accepted: 15 October 2020 / Published online: 29 October 2020

(C) Academic Psychiatry 2020

\begin{abstract}
"We have to acknowledge the progress we made, but understand that we still have a long way to go. That things are better, but still not good enough" - Barack Obama.
\end{abstract}

Although I attended medical school in a city with one of the largest Black populations in the country, where I now serve on the faculty, I received very little, if any, concrete education about how race impacts my patients and colleagues. In the current climate of the United States, where we are all being urged to explore our implicit and explicit biases, Black Mental Health: Patients, Providers and Systems has provided me with an entry into this area. Edited by three prominent psychiatrists, this text has begun to deepen my understanding of how racism affects the mental health of Black Americans and the experience of Black psychiatrists.

The book is divided into five parts, the first of which is titled "Reflections." In this section, the three editors of this volume and Dr. June Jackson Christmas write personal reflections of their experiences as Black psychiatrists in the US. The authors describe, for example, being the only Black resident in their class, being made a "symbol of black exceptionalism" ( $p$. 4), the importance of Black mentorship, the significance of personal psychotherapy with a Black analyst, and the paramount work of advocacy. Part I ends with a retrospective survey of eight Black psychiatrists, who reflect on May 1969, when at the American Psychiatric Association (APA) annual meeting, they were part of a group demanding a "change in the status quo to the APA hierarchy," which led

Mary K. Morreale

mmorreale@med.wayne.edu

1 Wayne State University, Detroit, MI, USA to "a dialogue that resulted in changes in the inclusion of blacks within organized psychiatry and reduced racial discrimination in mental health facilities" (p. 39). Sadly, among the main themes of these interviews was the sense that "racism/white supremacy is as pernicious today as it was in 1969" (p. 40).

Part two of this text, "Patient Care," covers a wide range of topics, including how being a woman or identifying as lesbian, gay, bisexual, transgender, and queer intersects with mental health, adult attention-deficit/hyperactivity disorder, psychotherapy, and biological therapies, and how the Black church has worked to improve the mental health of Black communities. A chapter on African Americans and the criminal justice system speaks both to larger societal issues, such as the perceived relationship between criminal activity and blackness, and concerns directly related to psychiatry, for example, the role of bias in forensic evaluations. The author of this chapter, Dr. Richard Dudley, concludes by urging research into the latter, stating: "There are no formal studies that have specifically explored the extent to which the work of forensic mental health professionals is influenced by explicit or implicit bias, and whether such bias contributes to the overrepresentation of African Americans in the criminal justice system. However, given that studies have determined that no one is free of implicit bias, and because anecdotal evidence regarding the impact of bias on forensic mental health evaluations is troubling, such formal studies are clearly indicated" (p. 74).

Part III, "Training of Black Mental Health Care Providers," includes a robust discussion of the lack of diversity within the field of psychiatry (e.g., only $2 \%$ of psychiatrists and $6.6 \%$ of psychiatry residents in the US are Black) and discusses ways that this lack could be remedied, such as early exposure to STEM (science, technology, engineering, mathematics) pipeline programs that begin in elementary school, and precollege 
and college programs that support aspiring physicians via mentorship. Perhaps indicative of the amount of work that is still needed within psychiatric residency education, the chapter on "Psychiatric Training and Black Mental Health" describes two cross-cultural "model curricula," neither of which specifically address concerns related to Black Americans.

Part IV of Black Mental Health: Patients, Providers and Systems discusses the current state of research related to African American populations. The first chapter, written by the late Dr. Carl Bell, introduces the concept of "bent nail research," which is based on an experience from the author's youth. Dr. Bell describes receiving a book filled with instructions for constructing a bookshelf, which he hoped to create to display his plastic models but being "too poor to afford the proper tools or building materials" (p. 257). "By rummaging through various alleys in Chicago, he was able to obtain the wood necessary for the shelves and vertical supports, and by using used bent nails and hammering them straight to be reused, he was able to construct the bookcase. Of course, it was a bit off center, because it leaned a bit to the right; but more importantly, it was functional and able to display the models" (pp. 257, 258). Although Dr. Bell clearly supported "pristine, formal academic research," given the dearth of clinical research on Black Americans, he encourages Black psychiatrists working in Black communities to engage in the "bent nail" approach of "rudimentary, basic clinical research" to further understanding of Black mental health and develop meaningful interventions (pp. 258, 267).

The final section of Black Mental Health: Patients, Providers and Systems carefully summarizes the text and concludes with a hopeful tone from the three editors, noting the "striking observation" that they have all "led lives of leadership in public systems of care" and reminding readers that "ingenuity and scholarship can lead to unique developments" (p. 337). But what is most clear from this volume is that the current approach to Black mental health is not nearly good enough, and academic psychiatrists still have a long way to go. This text is a concrete reminder that we must work to support Black medical students who show interest in psychiatry, diversify our residency programs, create curricula that allow a deeper understanding of culture, and encourage research that benefits the mental health of our Black patients and their communities.

\section{Compliance with Ethical Standards}

Conflict of Interest The author states that there is no conflict of interest.

Publisher's Note Springer Nature remains neutral with regard to jurisdictional claims in published maps and institutional affiliations. 